\title{
As origens da Política de Unidade Sindical no Brasil
}

Michel Zaidam Filho

Universidade Federal da Paraíba - Campina Grande

Astrogildo Pereira Duarte da Silva uniu indissoluvelmente o nome à causa dos comunistas brasileiros, desde pelo menos 1922. Contudo o fez de uma maneira muito peculiar. As características de sua militância, bem como a época cultural em que ela foi forjada, marcaram um tempo na história do PCB qualitativamente distinto das sucessivas épocas vividas por este partido até hoje. Esse velho militante foi herdeiro das tradições nacional-populares republicanas e, na condição de intelectual revolucionário, nunca disfarçou o seu interesse pela vida política do país, sempre intervindo nas grandes questões que agitaram a sociedade brasileira. Vem sem dúvida desta formação "jacobina" o matiz nacional imprimido à política do PCB em seus primeiros anos. E se cabe dizer que o Partido dos comunistas brasileiros foi, em seus inícios, "astrojildista", devemos entender com isto os indícios de uma elaboração original da política, que desapareceria do PCB durante as décadas posteriores.

Essas observações inciais querem chamar a atenção do leitor para o tipo de direção político-cultural que singularizou a primeira década da existência do PCB, sob a influência de homens como Astrojildo Pereira, Octávio Brandão, Leôncio Basbaum e outros. (1) Direção esta que, no terreno do sindicalismo, foi responsável pela introdução no Brasil da política de unidade sindical, a despeito da aparente continuidade verbal do anarcosindicalismo na prática sindical comunista e das orientações vigentes em cada momento da história da Internacional Comunista (IC).

(1) - Sobre isto, veja-se: Michel Zaidan. "PCB (1922-1929): nas origens da busca de um marxismo original". Voz da Unidade 25-03-83, e "O PCB e o movimento comunista internacional". Voz da Unidade 28-07-83, onde se busca mostrar a originalidade da elaboração teórico-político do $\mathrm{PCB}$ na época em que Astrojildo Pereira, Octávio Brandão, Leôncio Basbaum constituíam o "núcleo dirigente". do partido. 
Mas, para entender o significado real da política de unidade sindical no Brasil, é necessário antes de tudo recuperar algo do debate travado no interior do movimento anarco-sindicalista brasileiro sobre os princípios da organização sindical, em fins da década de 10 .

Na sequência da derrota que sofreram os operários da Companhia de Estradas de Ferro Leopoldina Railway, as principais lideranças do movimento libertário no Brasil depararam-se com uma grande crise nos meios sindicais do país. Resultado das perseguições policiais às sociedades operárias, ou da indolência dos trabalhadores, ou ainda das resoluções "extemporâneas" do $3^{\circ}$ Congresso Operário (que não teriam levado na devida conta a depressão do movimento operário internacional), o fato é que, neste período, muitas associações sindicais desapareceram ou ficaram assaz debilitadas. Os periódicos operários são escassos e deficientes e o número de greves decai sensivelmente (2). A este "sepulcral marasmo" em que se encontra jogado o proletariado carioca e paulista vem somar-se a "desorientação" e o "confusionismo" gerados pela Revolução Russa no movimento libertário brasileiro. As manifestações da imprensa anarco-sindicalista, nesta época, em relação à Revolução Socialista parecem ficar a meio caminho entre aprovar a frente comum das esquerdas em defesa da Re-

(2) - As condições de desorganização do proletariado, neste período, são denunciadas por toda a imprensa operária. Para os anarco-sindicalistas, veja-se: Antônio Vaz, "Necessidade de um Congresso" A Plebe V (197): 1, 20-12-22. Luigi Bertoni, "Nossa ação". A Plebe V (200): 1-2, 18-01-23. A. Vaz. "O próximo congresso". A Plebe V (194): 1, 04-11-22. Carlos Dias, "Uma palavra de estímulo". A Plebe $V$ (188) : 1-2, 12-08-22. Astrojildo Pereira, "A vitória dos gráficos". Movimento Comunista I (18-19): 112, 3/23. "Preparaçáio das massas". Movimento Comunista I (3):107, 25-03-23.

Com o estado de sítio, em 1922, a imprensa operária torna-se, mais ainda, precária e escassa. No Rio, Jornais como O Trabalho, A Revolução Social, O Libertário e outros são impedidos de circularem pela polícia. Em São Paulo, $A$ Plebe vai se mantendo com grandes dificuldades financeiras e um corpo redatorial muito fraco. Seriam frequentes, neste jornal, os pedidos de auxílio financeiro e contribuições jornalísticas. Por sua vez, as greves parecem refletir consideravelmente. Um levantamento feito em São Paulo dá conta da ocorrência de apenas 50 greves num espaço de dez anos (1920-1929). Ainda assim, nenhuma tendo caráter geral; três com caráter de categoria (gráficos/23, sapateiros/23, e tecelōes/24) e várias isoladas. A respeito, é de interesse mencionar o testemunho dado pela $A$ Plebe sobre a ausência de solidariedade da parte do conjunto da classe operária à greve dos sapateiros: "estas notas são feitas por nós, por isso iremos expandir também o quanto de amargura nos vai na alma, ao ver como a maioria da classe operária de São Paulo se mantém alheia e indiferente a tudo que the diz respeito. A presente greve, que deveria já ter suscitado um movimento geral de solidariedade moral para com a União dos Artífices em Sapatos, não foi suficiente para despertar o proletariado do sono letárgico em que está imerso". "A greve dos sapateiros" A Plebe VI (222):1, 10-11-23. No Rio de Janeiro, não se tem notícia de nehuma greve geral ou parcial. Apenas greves de categorias, como a dos tecelóes, de resultados incertos. 
volução e rejeitar as formas organizatórias e estatais criadas pelos bolchevistas russos. (3)

Neste contexto, tomam corpo as primeiras discussões tendo em vista a reorganização do movimento sindical brasileiro. Uma primeira indagação polariza as opiniões da Liderança anarquista: é necessário mudar algo na doutrina libertária para reanimar as lutas sindicais no País? Seria a frouxidão dos métodos de organização anarco-sindicalistas e a sua abstenção do "fazer política" os responsáveis pelas derrotas sofridas pela classe operária brasilieira? E a questão da firma particlo, com a sua disciplina e centralização?E a Ditadura do Proletariado, como seu autoritarismo? Estava a vitória da Revolução Russa a indicar os métodos da luta político-sindical mais compatíveis com as novas formas de dominação da burguesia imperialista?

O processo de amadurecimento dessas discussões no interior da vanguarda política do movimento operário brasileiro, sobre a validade ou não dos velhos princípios de organização sindical, está longe de ser claro e podemos nos basear apenas nas intervenções públicas de algumas lideranças, registradas na imprensa libertária da época: A Plebe, Voz do Povo, Spartacus, A Vanguarda e outros.

No bojo do debate que então se abriu sobre a Revolução Russa, o Bolchevismo e a Ditadura do Proletariado e seus refiexos no movimento operário brasileiro, é possível localizar os primeiros sinais de uma mudança de orientação na criação do Partido Comunista do Brasil, em 1919, ao qual estiveram ligadas muitas das principais figuras do anarco-sindicalismo brasileiro. Embora os autores expliquem o nascimento deste PC pelo entusiasmo despertado com o aparente caráter "libertário" da Revolução Russa e atribua à nova organização traços nitidamente anárquicos ("fundar uma sociedade sem classes, sem Estado, igualitária, livre"), não devemos nos esquecer de que o programa do PC preconizava "a arregimentação e educação do proletariado em geral para a posse dos poderes públicos único meio pelo qual poderá realizar este programa". E concluía decla. rando o seu voto de fidelidade "aos principios da Internacional".

É difícil não perceber aí a presença já de características "bolchevistas", no que tange à organização: a forma partido, a utilização do Estado, o vínculo com a IC etc.

Contudo, o debate só ganha contorno mais nítido quando aborda sem subterfúgios a questão dos princípios da organização sindical. A pouco

(3) - E o caso, por exemplo, do tom geral de muitos artigos sobre a Revo. lução Russa, a ditadura do proletariado e o Bolchevismo, escritos nos jornais $A$ Plebe, Spartacus e Vanguarda, antes de 1922, data da fundação do PCB. 
e pouco começam a aflorar as dúvidas sobre os velhos moldes do pluralismo sindical. Sob os influxos do centralismo e da disciplina sugeridos pelo "modelo bolchevista", as derrotas do movimento operário no Brasil passam a ser imputadas à frouxidão organizativa do anarco-sindicalismo, sobretudo aos princípios da organização sindical por oficio, que dava margem à existência de inúmeros pequenos sindicatos num mesmo ramo industrial. Neste sentido, uma primeira referência de Astrojildo Pereira à estrutura sindical dos "trabalhadores Internacionais do Mundo" (I.W.W.) lança um pouco de luz sobre os rumos que a discussão terminaria por assumir. Numa série de artigos escritos para $A$ Plebe e $A$ Vanguarda, Astrojildo procura chamar a atenção para o Congresso de preparação da Internacional Sindical Vermelha, que se realizaria em Moscou, a $1^{\circ}$ de maio de 1921. Aí estariam presentes duas potentes centrais sindicais - a Confederação do Trabalho da Rússia e os Trabalhadores Internacionais do Mundo representando as massas operárias dos EUA e da Rússia. Astrojildo alegava que, embora o Brasil não se fizesse representar de fato naquele encontro, lá estaria em "espírito" (4).

Mas o que atraía o militante anarco-sindicalista brasileiro era a inovação orgânica dos I.W.W.: a organização dos operários por ramos industriais. (5) Comparando este método com os vigentes até então no movimento operário brasileiro, Astrojildo afirmava que os nossos se caracterizavam por uma profunda dispersão corporativista, que se refletia por exemplo na "fraqueza geral das federações ante a força compacta e agressiva do inimigo". (6) "Nosso inimigo é um só", dizia, "e uma só deve ser a nossa força".

Referindo-se aos princípios organizativos dos I.W.W. Astrojildo destaca o caráter unitário, amplo da Central operária americana, enfatizan $\hat{l}^{\text {i }}$ também a unicidade de seu secretariado, do fundo de propaganda e ido centro de coordenação. Segundo ele,

"Os Trabalhadores Industriais do Mundo (I.W.W.) formam uma única grande união de todos os trabalhadores, com um único secretariado, um único fundo de propaganda e um único centro de coordenação.

E a grande união dos trabalhadores concretizando o velho lema: um por todos, todos por um.

(4) - Cf. Astrojildo Pereira, "A Internacional Sindical Vermelha". Voz do Povo, 01-05-21.

(5) - Cf. Astrojildo Pereira, "Nada de precipitação". A Plebe, 11-06-21.

(6) - Idem.

(7) - Idem. 
Para as questões técnicas e profissionais, os I.W.W. se dividem e subdividem em departamentos e uniões industriais, aliás sem limites de fronteiras, nacionais ou internacionais". (8)
\end{abstract}

Impressionado com a unicidade sindical dos I.W.W., o velho militante recomendava aos camaradas o estudo e a discussão desses princípios, afirmando que, se fosse o caso de os trabalhadores brasileiros adotarem o "modelo unitário", havia dois caminhos por onde começar: a organização geral e única nas cidades e a organização única, nacional, de determinados ramos de indústrias. E indicava preferencialmente a União dos Operários em Fábricas de Tecidos para iniciar a experiência, já que era em parte assim formada. (9)

E de interesse fazer aqui uma pequena pausa, para esclarecer a posição dos anarco-sindicalistas brasileiros sobre esta questão. Embora se impute habitualmente aos libertários a pluralidade sindical, é necessário advertir para a distinção que fazem entre os núcleos propriamente "anarquistas" e os sindicatos operários. Para alguns, no que diz respeito aos sindicatos, haveria uma certa concordância em relação ao princípio da unicidade sindical, resguardando-se o extremo federalismo para os núcleos libertários, em sua ação de propaganda e agitação entre os operários. Já outros entendem abertamente o pluralismo às associações sindicais, organizando-as a partir de declarações de princípios anarco-sindicalistas. (10)

Na polêmica com os adeptos do "modelo bolchevista", o que aparece em questão não é a unicidade ou pluralidade sindicais, mas sim, a vinculação do sindicato ao partido ou ao Estado. Em síntese, na avaliação da fraqueza do movimento sindical brasileiro, os anarco-sindicalistas se dispõem a reconhecer a necessidade de mudar os "métodos" de organização

(8) - Cf. "Pela reorganização Proletára". A Plebe, 28-05-21.

(9) - Idem.

(10) - Para a divergência de pontos de vista entre anarco-sindicalistas, vejase: "Pela reorganização Proletária". A Plebe, 28-05-21. no que diz respeito a Edgard Leuenroth; "Manifesto-programa". A Plebe V (177):1-4, 18-03-22; Federação dos Trabalhadores da Região Central do Brasil. "Declaração de princípios". A Plebe VI (203): 2, 24-03-23 e o "preâmbulo" desta última publicada em A Pátria, 06-06-23. Para a polêmica suscitada pelas diferentes opiniões, veja-se: José Soares, "Ainda sobre a declaração de princípios da FF. dos T. da R. C. do Brasil" t. A Plebe VI (205):2, 24-03-23; Domingos Braz, "Cogita-se da fundação da Federação dos Trabalhadores da Região Central do Brasil. Opinião de um camarada de Petrópolis". A Plebe V $(202): 2,17-02-23$. Adolfo Marques da Costa, "A propósito da declaração de princípios da Federação dos Trabalhadores da Região Centro do Brasil", A Plebe VI (204):2, 10-03-23? Domingos Braz, "Cogita-se da fundação da Federação dos Trabalhadores da Região Centro do Brasil", e Pedro A. Mota, "Em torno do Sindicalismo". A Plebe VI (213): 3, 07-07-23. 
- rumo ao sindicato único de indústria, (11) mas não os "princípios" doutrinários - sempre antipartidários, antiestatais.

Assim, o que dividiria, separaria uns e outros seriam as concepções inclusivas da organização sindical - o anarco-sindicalismo e o bolchevismo -, o que permitiria em tese uma frente de trabalho em comum nos meios operários. Mas, na medida em que foram se explicitando as opções ideológicas básicas, a prática sindical foi se estilhaçando, a despeito da pregação unitária da militância sindical.

No início dos anos 20, Astrojildo Pereira tomaria por fim a iniciativa de realizar inúmeras reuniões para discutir o desdobramento da Revolução Russa $\theta$ o posicionamento de revolucionários brasileiros em face dela. Segundo ele, a partir dessas discussões, foi se impondo a constatação de que qualquer obra de reorganização do movimento sindical teria de se inspirar no "programa" da IC: concentração, homogeneização, disciplina, ditadura. Fora disso, seria reformismo franco ou disfarçado (socialistas) ou dispersão de energias e parolagem (anarquistas). (12) Dessa forma, paulatinamente ía se vinculando a sorte do movimento operário no Brasil e uma opção ideológica determinada: o bolchevismo russo, malgrado o caráter ecumênico inicial da Revolução Russa e a pregação da unicidade sindical. Não se explica por outra razão, aliás, a preferência de Astrojildo por um "comitê" de dez homens firmes, seguros e devotos, do que cem indecisos, flutuantes e refratários, na obra da reorganização sindical...

Em artigo escrito em fins de 1921, descrevendo o panorama sindical brasileiro e as tarefas de organização do movimento "comunista", 'ele dizia:

"Atualmente, a atenção dos militantes se concentra em dois pontos capitais: a necessidade de conquistar as grandes massas operárias para a organização e o sistema industrial como base dessa organização". (13)

Para isso, deveria ser formado em breve um comitê de organização e orientação, composto de militantes que, à semelhança dos CC, SS.RR. franceses, estabeleceria uma rede homogênea e disciplinada de núcleos trabalhando nas organizações já existentes e nas que se criassem, tudo segundo um plano previamente traçado. (14)

(11) - Cf. Edgard Leuenroth, "Pela reorganização Proletária". A Plebe, 28-05-21, e "Manifesto-programa". A Plebe V (177):1-4, 18-03-22, especialmente os ítens "a nossa organização" e "a nossa ação na organização do proletariado".

(12) - Cf. Astrojildo Pereira, "Carta a Rodolfo Felipe", 20-08-21, apud Edgard Rodrigues, Nacionalismo e cultura social (Rio: Laemmert, 1968), p. 407.

(13) - Cf. Astrojildo Pereira, La obra de reconstrucción social", El obrero Ebanista, apud Edgard Rodrigues, idem, p. 414.

(14) - Ibidem. 
Segundo Astrojildo, a ação desses comitês teria três aspectos: $1^{\circ}$ ) a reorganização dos sindicatos "vermelhos"; $2^{\circ}$ ) a reorganização sindical por ramos industriais daqueles sindicatos sem organização até aquela data; $3^{\circ}$ ) a conquista dos velhos sindicatos "amarelos" que, a despeito de serem muito fortes, eram caracterizados por um extremo corporativismo. (15)

Apesar da aparente continuidade que flui, nesses escritos, da recorrente pregação unitária do trabalho sindical, é preciso advertir para a relevante decisão tomada por Astrojildo nesta época em criar os "núcleos comunistas", tendo em vista a constituição dentro em breve do Partido Comunista, seç̧ão brasileira da Internacional Comunista. Isto porque o programa da IC preconizava uma política sindical muito específica naquele momento e que se chocaria, de certa forma, com a busca da unicidade sindical no Brasil.

Como chamou a atenção Claudin em sua obra sobre a IC, a organização internacional dos comunistas assimilou totalmente a concepção que os líderes bolchevistas tinham da marcha da revolução mundial e do tipo de partido revolucionário necessário. (16) Tal concepção correspondia a uma "estratégia ofensiva a curto termo", decorrente da análise feita por Lênin sobre a conjuntura européia, onde se via um potencial revolucionário que deveria ser explorado (1919-1921). Mas, para isto, seria preciso a criação de "um partido mundial da revolução", em face do reformismo da social-democracia européia e de sua ação entorpecedora sobre a classe operária. Daí então a origem das características e da política da IC.

No contexto dessa estratégia, entre as características da IC aquela que teria um papel determinante era a sua intransigência para com o Reformísmo e o Centrismo (considerados assim como os únicos obstáculos à irrupção da revolução socialista na Europa) e a preocupação de se tomar, desde o princípio, medidas drásticas para assegurar a pureza doutrinária dos novos partidos "comunistas". Neste sentido, avultam as famosas "21 condições para a admissão de um partido comunista à IC", qualificadas por Claudin como "modelo de sectarismo e método burocrático na história do movimento operário". (17) Para os propósitos deste trabalho, será necessário apenas enfatizar a obsessiva preocupação das "21 condições" em hostilizar abertamente todo e qualquer contato entre comunistas, reformistas e centristas e o estabelecimento da aceitação integral e incondicional das aludidas "condições", como critério para o reconhecimento

(15) - Cf. Astrojildo Pereira, "Carta a Rodolfo Felipe", 20-08-21, in op. cit., p. 407.

(16) - Cf. Fernand Claudin, La crisis del movimento comunista. Del Kominte al Cominform (Madrid: Ruedo Ibérico, 1970), Vol. I, p. 76.

(17) - Cf. Fernand Claudin, Idem, p. 78. 
dos "verdadeiros comunistas". (18) Sobre as consequências dessa estraté. gia para o movimento sindical, vale a pena reproduzir a judiciosa observa. ção de Claudin:

"As 21 condições significavam, na prática, que os comunistas organizariam as cisôes do movimento operário em toda linha e que a organizariam, ademais mecanicamente, e não através de um processo político e ideológico que permitisse aos trabalhadores convencerem-se de sua necessidade". (19)

Desta forma, a IC não só cerraria as portas a um grande número de socialistas e sindicalistas que simpatizavam com a Revolução Russa e concordavam com os objetivos revolucionários da nova Internacional, como atraía para o seu seio indivíduos desligados das massas, a quem era muito mais fácil opor-se às antigas organizações e afirmar-se sob o novo manto ideológico. Assim, sob a influência das 21 condições - conclui Claudin - e, em geral, de todo o método adotado pela IC na luta contra o reforn mismo e o centrismo, implantou-se nos partidos comunistas desde o primeiro dia um espírito sectário e dogmatizante, envolto num verbalismo revolucionário que dissimulava a perda de pé na realidade. (20)

Imbuída do espírito das " 21 condições", a pregação unitária de Astrojildo Pereira iria na verdade se defrontar com uma flagrante dualidade de estratégias e táticas, oriundas de momentos diversos da história da IC (1919-1921; 1921--924). Coexistiram no PCB, ao longo dos anos 20, a "estratégia ofensiva a curto termo", que punha a ênfase na cisão do movi-l mento operário, través da criação de "núcleos comunistas" nas velhas organizações sindicais da classe operária, para disputar a hegemonia com os socialistas e centristas sobre ela; e uma "estratégia defensiva" que, em face do refluxo do movimento operário europeu e suas conquistas políticas e sindicais, passaria a privilegiar então a criação de "frentes únicas" sindicais e socialistas (com reformistas, centristas, cristãos, liberais, etc). em caráter provisório. (21)

É pois sob a vigência dessa dualidade que devemos apreciar a política de unidade sindical dos comunistas brasileiros na década de 20. Muitos são os artigos de Astrojildo Pereira neste período que voltam a sua atenção para o problema da unidade sindical dos operários. Vejamos alguns:

(18) - Cf. Fernand Claudin, Ibidem, p. 78.

(19) - Cf. Fernand Claudin, op. cit., p. 79.

(20) - Cf. Fernand Claudin, op. cit., p. 79.

(21) - Fernand Claudin, op. cit., pp. 77-79. Em relação ao PCB, veja-se Michel Zaidan, "Política Social e Resistência Operária", in Pão-e-pau: Politica de governo e sindicalismo reformista no Rio de Janeiros 1923-1926. Dissertalção de Filosofia e Ciências Humanas, da UNICAMP, 1982, p. 252 e ss. E, "Construindo o PCB; 1922-1924", Temas de Ciências Humanas (7): 115-129, 1980. 
"No terreno sinndical, bater-nos-emos energicamente contra todas as divisões e fragmentação. A organização sindical para responder a seus fins específicos deve assentar sobre uma base econômica comum a todos os trabalhadores".

"O trabalho reorganizador de agora deve, por consequência, obedecer a este duplo critério: chamar aos sindicatos as massas não-organizadas e conquistar a solidariedade das velhas Uniões Corporativas. E isto, evidentemente, só pode ser feito segundo um programa largo, concreto e preciso, alheio a quaisquer sectarismos estreitos, a quaisquer particularismos ideológicos".

"O sindicato, por definição, é um organismo especificamente econômico, destinado a agremiar todos os trabalhadores, sem distinção de partidos... uma polîica ou ideologia virá, depois, em consequência, precisamente, da influenciação em seu meio das várias correntes ideológicas e partidárias. Nisto consiste justamente um dos trabalhos mais sérios dos PCs".

"O movimento operário no Brasil só poderá tomar corpo e progredir se obedecer a um plano de conjunto, a uma direção firme e definida. Para isto, necessário se torna organizar o mais breve possível uma Confederação Geral dos Trabalhadores, apoiada sobre bases que permitam o ingresso de todas as categorias de assalariados de todos os partidos e tendências. No terreno da luta pelas reivindicações imediatas, todos os esforços se devem unir... no correr da luta, os trabalhadores vão adquirindo consciência de seu papel histórico e das suas possibilidades de ação e só então estarão em condições de optar entre as diversas correntes políticas, as diferentes doutrinas que têm por fim a libertação dos trabalhadores". (22)

(22) - Cf. Astrojildo Pereira, "A reorganização sindical". Movimento Comunista I (6):143-4, 5/1922; "A organização sindical das massas". Movimento Comunista II (15):24, 1/1923; e, Movimento Comunista II (18-9):112, 3/1923. Comentando a palavra-de-ordem da IC, neste período, diria Astrojildo: "Esta, a significação histórica das operalções cisicionistas verificadas, no movimento operário mundial, durante a após a guerra. Levadas a bom termo, como já vimos, com a constituição definitiva da IC e ISV, trata-se agora de canalizar todo o movimento para o seu terreno próprio da luta de classes e de enterrar para sempre os membros gangrenados e já seccionados. E este é o problema da formação da "frente única proletária". Frente única quer dizer: o movimento operário unânime em seu terreno próprio de classe. Ou, por outras palavras, coordenação, concentração, centralização de todas as forças proletárias sob uma direção única para o fim único da emancipação dos trabalhadores. Conscientemente ou instintivamente, todas as facçốes do movimento operário mundial compreendem que sua salvação, isto é, sua emancipação depende da unificação e homogeneização de seus esforços. Dessa compreensão nasceu a palavra-de-ordem "frente única". O Paiz, 21-09-23. 
Embora alçada à condição de princípio desde o artigo-programa do Movimento Comunista, (23) a política de unidade sindical dos comunistas brasileiros penderia consideravelmente para o divisionismo, privilegiando na prática a estratégia das "21 condições". (24) É provável que boa

(23) - Cf. "Movimento Comunista". Movimento Comunista I (I):1, 1/1922, onde se diz: "No terreno sindical, bater-nos-emos energicamente contra todas as divisões e fragmentações. A organização sindical, para responder a seus fins específicos, deve assentar sobre uma base econômica comum a todos os trabalhadores. De conformidade com este critério amplo e positivo, combateremos todos os desvios, todas as deturpações, todos os germes de dissolução que surjam no interior dos organismos sindicais. Preconizamos a mais íntima e estreita ligação orgânica e funcional entre todas as unidades sindicais locais, nacionais e internacionais. Somos pela frente única de combate do proletariado de todo o mundo, sob a bandeira revolucionária da Internacional Sindical Vermelha".

(24) - A esse respeito, veja-se o depoimento de Joaquim Barbosa, o responsável pela seção sindical do partido: "convém notar que as campanhas, movidas pelo partido contra os chefes amarelos dos trabalhadores, só têm sentido no meio da massa, quando estão prestigiadas por uma vanguarda que se encarregue de dificultar a defesa do traidor ou dos traidores atingidos.

Tem o partido núcleos nestes sindicatos capazes de neutralizar ou mesmo dificultar as arremetidas dos nossos adversários? Não tem, infelizmente, sucede que as nossas campanhas nestas condições, em vez de refletirem satisfatoriamente entre as massas, pelo contrário, ferem-nas, fazem com que, dado o seu atraso, se julguem elas atacadas e neste caso os resultados são, por isso mesmo, negativos". Cisão do Partido Comunista, Rio de Janeiro, Publicação do Grupo Braço e Cérebro, 1928, p. 14 e "Uma tentativa infrutífera'. Diário Carioca, 20-07-28. Veja-se também: Octávio Brandão, Combate e Batalhas; São Paulo, Alfa-Ômega, 1978, pp. 250-1, onde se diz: "Os sindicatos dos sapateiros e da construção civil eram duas posiçôes do anarquismo e anarco-sindicalismo. Neles, os comunistas cometeram erros grosseiros. Fizeram ameaças aos adversários. Praticaram atos de indisciplina. Tentaram cindilos. Isto impediu a conquista desses dois sindicatos. A luta prolongou-se durante vários anos.

Os comunistas dividiram o sindicato dos sapateiros, violando a decisão da CCE do PCB. O velho sindicato anarquista vegetou miseravelmente. O novo sindicato, dirigido pelos comunistas, levou uma vida difícil sob os golpes do estado de sítio. Depois, aproveitou o período de relativa estabilidade em 1927/28 e desenvolveu-se. Mas ficou debilitado com a reação de 1929.

O sindicato da construção civil, dirigido pelos anarquistas, também vegetou. Os comunistas organizaram um novo sindicato que progrediu em 1928-9 e caíu sob os golpes da reação depois de junho de 1929.

Em 1923, agravou-se a luta entre o PCB e os anarquistas e anarco-sindicalistas. A Federação dos Trabalhadores do Rio de Janeiro era débil. Os anarquistas e anarcosindicalistas cindiram-se. Criaram a Federação Operária do Rio de Janeiro, com os sindicatos de construção civil, sapateiros e dissidentes do centro cosmopolita, num total de 1.500 membros. A Federação dos Trabalhadores do Rio de Janeiro com os sindicatos dos padeiros, alfaiates, carpinteiros, canteiros e marmoristas, e um total de 3.500 membros. O PCB tratou de reforçá-las. Esse fato provou que o anarquismo era cisiocionista e contribuiu para desmascará-lo". Para as versões anarcosindicalistas, veja-se: "Manifesto da União dos operários em construção civil" apud Edgard Rodrigues. Novos Rumos. Pesquisa social. Rio de Janeiro, Mundo Livre, 1979, pp. 29-33 e Maurício Vilhena. "Os bolchevistas no sindicato". A Plebe VI $(210): 2,26-05-1923$. 
parte das razões responsáveis por essa direção seja atribuível ao sectarismo dos anarco-sindicalistas do Rio de Janeiro que, frente a "invasão", agora, dos comunistas nos meios sindicais cariocas, decidiram organizar as suas associações na base de declarações de princípio - "libertárias". Contudo, as confissões de diversos militantes comunistas, bem como a sua prática sindical efetiva nos permitem dizer que, na melhor das hipóteses, a política de "frente única" sindical do IC sempre pressupõe a hegemonia do Partido Comunista sobre os seus aliados. (25) A propósito, é de interesse observar rapidamente como foi, de fato, realizada a política de "frente única" dos comunistas no Brasil: numa conjuntura de permanente ilegalidade, o PCB se serviria de uma "Confederação Sindicalista-Cooperativista”, mais ou menos governista e patronal, para ter acesso aos sindicatos e

Como é fácil perceber por uma simples leitura desses depoimentos, a tática empregada aí pelos ativistas sindicais do partido é a das " $21^{\mathrm{a}}$ condições", ou seja, a do divisionismo.

(25) - Cf. José Oiticica, "Resposta Necessária" V. A Plebe VI (226): 2, 05-01-1924, onde afirma: 'Quanto à frente única sempre o fizeram, como já acentuei, os anarquistas. Nossa dissidência com a IC está somente em que a IC não quer frente única dos trabalhadores, mas frente única dos trabalhadores dentro do partido comunista'. De sua parte, os comunistas terminaram por reconhecer essa maneira de encarar a "frente única": "mais do que nunca torna-se necessária a disciplina no seio das diversas organizaçôes obreira do país, em torno do Partido Comunista recém-fundado no Rio de Janeiro, que indiscutivelmente corresponde às necessidades do momento; trabalhar com energia pela sua propaganda, tornando-o conhecido dos trabalhadores, como familiarizar-se com os seus princípios, esforçando-se pela adesão do maior número de organização proletárias deve; ser o nosso lema neste momento". Álvaro Teixeira, "Ocasião oportuna", A Voz Cosmopolita III (44). 2, 13-01-1923. Veja-se também: Michel Zaidan. "A questão da unidade sindical" Voz da Unidade, 21-07-83: "Inspirados no leninismo da III IC, os comunistas brasileiros herdaram uma concepção do trabalho sindical e de massas que associava umbilicalmente unidade e hegemonia, ou melhor: unidade sob hegemonia. Embora reiteradamente se declarasse a favor da mais ampla unicidade sindical, em face da igualdade econômica a que se acham submetidos todos os membros de um mesma categoria profissional, esta unicidade sempre entendida pelo PCB como uma condição para o exercício de seu domínio, não apenas sobre o conjunto dos membros de uma dada categoria profissional, mas também sobre as demais tendências político-partidárias atuantes no movimento sindical. Tal orientação esteve presente nas relações do Partido com as organizações de frente política e entidades pluralistas. Aí, de maneira semelhante, a palavra-de-ordem dos comunistas brasileiros era trabalhar no seio destas organizações para fortalecer a influência do $\mathrm{PCB}$, em vista de colocá-las sob a sua direção. Neste sentido, por exemplo, são muito ilustrativas as passagens de resolução política do III Congresso Nacional do PCB, em 1928-9, sobre "o trabalho do Partido Comunista Brasileiro nas diversas organizações de massas além do BOC e dos sindicatos". Eles expressam exatamente essa tendência de "trabalhando ativa e sistematicamente nessas organizações de massas exteriores ao Partido, conseguiremos enraizar cada vez mais nossa influência comunista no seio das massas laboriosas", com o objetivo de submetê-las "à hegemonia do PCB". Cf. O III Congresso do Partido. A todas as organizaçôes de base, a todos os membros do Partido. Rio de Janeiro, 1928, p. 3, mimeografado. 
publicar os seus comunicados aos trabalhadores, ao tempo em que assimilaria os anarco-sindicalistas brasileiros aos social-democratas reformistas europeus (ou aos "oportunistas de esquerda" a que se refere Lênin em $O$ Estado e a Revolução). (26)

Essa postura em relação ao movimento sindical e de massas, bem como em relação às demais tendências político-partidárias atuantes nos meios sindicais, onde não levou diretamente ao divisionismo, com o subsequente enfraquecimento do movimento operário, muito contribuiu para manter no atraso político os trabalhadores, que continuavam assim como objetos da sua emancipação e não se tornavam, em consequência, sujeitos da sua ação política, mediante um processo de auto-organização. Sob a hegemonia de reformistas, anarco-sindicalistas ou comunistas, os trabalhadores não se emancipavam. Orientados a uma prática de depuração partidária dos sindicatos onde desenvolviam a sua atuação, os militantes comunistas favoreceram muitas vezes a desagregação dos organismos de massa, ao entrarem em dispuita pela direção destas entidades com os anarco-sindicalistas, socialistas e sindicalistas "amarelos". A este respeito, a confissão mais franca que se conhece é o depoimento de um antigo dirigente sindical do PCB, onde são reveladas as nocivas consequências da política instrumentalista levada a cabo no sindicato dos têxteis do Rio de Janeiro, em meados da década de vinte, pelos ativistas sindicais do Partido. Acrescente-se a isto que tais revelações vir-se-iam parcialmente ratificadas pelas resoluções do III Congresso Nacional do PCB, poucos meses depois. (27)

Essa nefanda tradição de juntar para instrumentalizar, sob a pregação corporativa e unitária do trabalho sindical, fez carreira na história da militância operária dos comunistas brasileiros, alimentando sólidos preconceitos em vários setores do movimento sindical e de massas deste País, que fazem ler sempre no discurso unitário dos comunistas uma solerte e camuflada tentativa de manipulação. $\mathrm{Na}$ verdade, os fundamentos dessa concepção - profundamente arraigada entre nós - vão além das origens do comunismo brasileiro e deitam raízes no "marxismo- leninismo" mesmo da II Internacional Comunista: a concepção "tática", "instrumental" da democracia, do pluralismo ideológico, da frente política, onde os interlocutores são sempre reduzidos à condição de "companheiros de viagem" prestes a serem desembaraçados do nosso projeto político, quando não mais convém mantê-los ao nosso lado...

(26) - Cf. Astrojildo Pereira, "O Caminho da Unidade Sindical", La correspondência., 15-3-27, e Michel Zaidan, "Política social e resistência operária". In: Pão-e-pau: Política de governo e sindicalismo reformista no Rio de Janeiro: 19231926, p. 256 e especialmente a nota no 65, deste capítulo, p. 292, e "Construindo o PCB: 1922-1924", Temas de Ciências Humanas (7): 115-129, 1980.

(27) - Cf. Michel Zaidan, "A questão da unidade sindical". Voz da Unidade, 27-07-83, p. 14. 
A superação definitiva de uma tal concepção da unicidade sindical passa hoje necessariamente pela ruptura com o "modelo bolchevista" de organização e da política, concebendo-se a democracia como a centralidade necessária de qualquer projeto de construção socialista no Brasil e fortalecendo-se, em consequência, o peso das entidades de massa neste projeto. Neste sentido, os comunistas brasileiros já deram os primeiros passos, ao acenarem com uma alternativa democrática (28) para a crise estrutural da sociedade brasileira. Mas se querem resgatar com radicalidade o melhor do legado teórico-político do velho Astrojildo Pereira, devem levar à frente a revisão de sua política de unidade sindical, sintonizando-a com a diversidade social criada pela modernização capitalista em nosso País.

(28) - Cf. Projetos de manifesto, programa e estatutos do Partido Comunista Brasileiro. Brasília, 1983, pp. 9-10: " $E$ por isto (por uma alternativa democrática e nacional para a crise, que abre o caminho para o socialismo) que lutamos por uma democracia de massas, para que os cidadãos possam manifestar as suas idéias e aspirações através de uma rede de organizações de base (sindicatos, comissões de empresa, associações de bairro e profissionais, movimentos democráticos e patrióticos, comunidades de inspiração religiosas, etc.) e de instituições políticas e sociais, partidos e agrupamentos aptos para intervir na solução de problemas específicos que lhe dizem respeito na decisão das grandes questões nacionais, no controle do Estado e da gestão social". E ainda: "transformando democraticamente o Estado, modificando o caráter e as funções das instituições estatais e conjugando-se com a rede de organizações de base, respeitadas em sua autonomia, na articulação das formas representativas como instrumentos de democracia de base, a democracia de massas favorecerá a superação do capitalismo dependente e propiciará os suportes sociais para um projeto nacional hábil para galvanizar e reorganizar toda a sociedde". (*) - Abreviaturas: AC - L'Antiquité Classique. BHAC - Bonner Historia-A ugusta-Colloquium. BMC - CARSON, R.A.G., Coins of the Roman Empire in the British Museum. London, the Trustees of the British Museum, 1962. CIL - Corpus Inscriptionum Latinarum. GCS - Die griechischen christlichen Schriftsteller der ersten (drei) Jahrhunderte. ILS - DESSAU, H., Inscriptiones Latinae Selectae. IGrR - Inscriptiones Graecae ad res Romanas pertinentes. JRS - Journal of Roman Studies. MGM Auct. Ant. - Monumenta Germaniae Historica (Auctores Antiquissimi). OGIS - DITTENBERGER, H., Orientis Graeci Inscriptioones Selectae. P. Oxy Papiro Oxirrinco. RFIC - Revista di Filologia $e$ di Istruzione Classica. 